\title{
Research on Concrete Durability Improving for Existing Island-Building and Its Application
}

\author{
Mao Jianghong, Zhu Yaofeng, Xu Fangyuan, Jin Weiliang, and Xu Yidong \\ Ningbo Institute of Technology, Zhejiang University, Ningbo Zhejiang 315100, China \\ Zhu Yaofeng and Xu Chen \\ Chongqing Jiaotong University, Chongqing 400074, China \\ Jin Weiliang \\ Institute of Structural engineering, Zhejiang University, Hangzhou Zhejiang 310085, China
}

\begin{abstract}
China's coastal cities contain a large number of islands with abundant human activities, in which buildings are in a typical marine corrosion environment and the corrosion of reinforced concrete structures is very prominent. This paper makes research work on two aspects: (1) the durability assessment and durability improvement after a thorough investigation of the architecture of Xiangtan County, Ningbo city, on an island and (2) the application research of the bidirectional electromigration rehabilitation (BIEM) technology to enhance the durability of existing island building life. This paper designs a set of BIEM equipment based on solar power supply and develops a BIEM control system with an automatic control system based on $3 \mathrm{G}$ networks, which realized the functions of indoor BIEM parameter setting, data receiving and wire breaking, and so on. The research results show that the complete set of BIEM techniques proposed in this paper can effectively remove the chloride ion in the concrete and transfer the rust inhibitor to the surface of steel bar. The research results have important effects on the durability and safety of island buildings.
\end{abstract}

Keywords: island building, concrete durability, bidirectional electromigration rehabilitation

\section{INTRODUCTION}

According to the different area, there are 13 big islands in the area of $100-2500 \mathrm{~km}^{2}$ and nearly 120 islands of $5-99 \mathrm{~km}^{2}$ in China. There are 6536 islands with an area of more than $500 \mathrm{~m}^{2}$, which is about $0.8 \%$ of the national land area, among the 450 inhabited islands.

Durability research in foreign countries can be traced back to the 1840s. The first research work on the destruction of concrete by seawater was done by the French engineer Vickar (Mehta, 1991). Academic conferences had been held frequently in 1960s and peaked in the 1990s. These conferences focused on improving the durability design, assessment, and maintenance of concrete structure in Europe ( $\mathrm{Li} \&$ Liu, 1999). The research emphasis on the durability of concrete structure is transferred to the coastal area in the recent 10 years. By drawing lessons from foreign research experience, domestic researchers have also made some research results (Ding \& Cui, 2000; Jin \& Zhao, 2001, 2002; Yan, You, \& Cui, 2000; Zhao \& Jin, 2002; Zhao \& Wan, 2001). Many reinforced concrete buildings in the island have different degrees of corrosion problems. Exposed in the atmosphere at a distance of about $250 \mathrm{~m}$ to the sea, the Q235 steel cannot meet the performance requirements 5-7 years later, while after 13 years, it can still meet in the interior environment (Wei, 2001). The corrosion is more significant if exposed to the marine environment directly. Currently, the existing methods include cathode protection, electrochemical and alkali method, electro deposition repair method, electrochemical chloride method, and electro osmosis rust method (Jin et al., 2015). However, there is a shortage in applying the abovementioned methods to repair the component durability: they cannot move out the chloride ion to reduce the gap rate of protective layer and increase the concrete density at the same time.

This paper carried out research of island building in the Xiangtan County in Ningbo as the object. The buildings are in a special geographical environment. The measured results show the chloride ion content in main bearing member is significantly higher than the "Concrete quality control standard" (GB50164-92). The project based on bidirectional electromigration rehabilitation (BIEM) technology developed a BIEM complete set of equipment suit for island buildings in engineering application. The results show that BIEM technology can significantly reduce the chloride 
ion concentration in concrete, so as to enhance the durability of island building.

\section{THE BASIC PRINCIPLE OF BIEM TECHNOLOGY}

The principle of BIEM technology is shown in Figure 1.

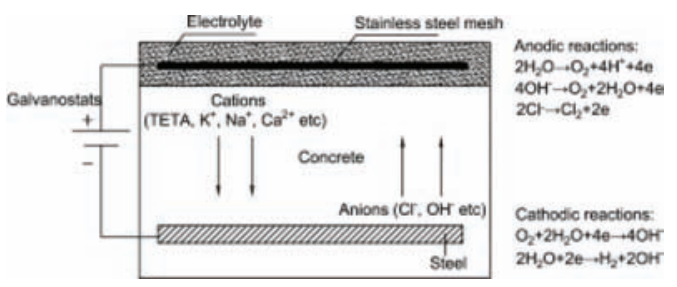

Figure 1. Principle diagram of BIEM technology.

The steel bar in the reinforced concrete structure works as the cathode, the stainless steel or titanium alloy sheet on the surface of the structure as anode, and the arranged anode electrolyte containing rust inhibitor in the range of the anode and the structure surface, when applied direct current voltage between the anode and cathode (Xu, Jin, \& Zhang, 2014). Under the action of an external electric field, the rust inhibitor cations in the electrolyte will enter the protective layer and migrate to the cathode (steel bar), while the $\mathrm{Cl}$ - in the test piece will migrate to the anode (Zhang, 2012). When the rust inhibitor concentration reaches a certain value in the surface of steel bar, the steel surface will form a layer of dense protective film, separating the chlorine ion, oxygen, and other corrosive media from the steel bar to play the role of rust resistance (Nmai, 2004). At the same time, due to the continuous reaction in the cathode, the $\mathrm{OH}$ continues to produce making the $\mathrm{pH}$ value in the pore fluid near the steel bars increased, which is beneficial to the passivation of steel bars.

\section{DETECTION AND EVALUATION ON THE CONSTRUCTION STATUS OF AN ISLAND}

\subsection{Structure testing content}

This project mainly carries on the exterior detection of island village building, intensity of the main components, indoor bearing capacity test, and durability. Through the research, there is a need to make more comprehensive detection of the island villages: the specific detection of position in island buildings with different environmental condition and different distances from the coast and the detection of different parts in the same building.

\subsection{Thickness of protective layer}

"Code for design of reinforced concrete structures" (TJ10-74) specified that regardless of the environmental category the slab cover thickness is $10 \mathrm{~mm}$ and the beam is $25 \mathrm{~mm}$ when reinforced concrete slab thickness is less than $100 \mathrm{~mm}$. Compared to the existing structures, the "Code for design of concrete structures" (GB50010-2010) provides that the island construction is in the category of three environments. The minimum thickness of the floor protection layer is specified as $40 \mathrm{~mm}$ and the beam is $50 \mathrm{~mm}$. Therefore, the cover thickness of the island building beam and slab is low.

Table 1. Detection value of protective layer thickness (mm).

\begin{tabular}{lllllll}
\hline Position & \multicolumn{4}{c}{$\begin{array}{c}\text { Value of protective layer } \\
\text { thickness }\end{array}$} & $\begin{array}{c}\text { Average } \\
\text { value }\end{array}$ \\
\hline Bottom of beam & 28 & 28 & 28 & 28 & - & 28 \\
Floor slab 1 & 24 & 22 & 24 & 20 & 19 & 21.8 \\
Floor slab 2 & 18 & 27 & 18 & - & - & 21 \\
\hline
\end{tabular}

\subsection{Test results of carbonation depth}

Carbonation depth test value of floor bottom is $1.0 \mathrm{~mm}$ and beam side is $6.0 \mathrm{~mm}$. However, many investigations show that even if the concrete carbonation depth is relatively small, the steel is also vulnerable to corrosion such as in the case of high chloride content environment.

\subsection{Detection results of chloride ion concentration}

Detection steps are as follows: (1) select concrete of floor slab, beam, and balcony cantilever in the building to take powder; (2) use the 12-mm diameter drill bit to take powder for $5 \mathrm{~mm}$, a layer with three holes; (3) screen with a sieve of $0.3 \mathrm{~mm}$ size pore; (4) weigh $2.0 \mathrm{~g}$ powder sample; (5) dissolve it in $20 \mathrm{ml}$ deionized water with $24 \mathrm{~h}$ of immersion; and (6) take RCT test to measure the content of $\mathrm{Cl}^{-}$in each layer of concrete.

Table 2. Chloride ion content form at different depths of each position (company, \%).

\begin{tabular}{lccccccc}
\hline & \multicolumn{7}{c}{$\begin{array}{c}\text { Chloride ion content in different depths (mm) } \\
\text { to structure surface (\%) }\end{array}$} \\
\cline { 2 - 8 } $\begin{array}{l}\text { Measuring } \\
\text { position }\end{array}$ & $\mathbf{5}$ & $\mathbf{1 0}$ & $\mathbf{1 5}$ & $\mathbf{2 0}$ & $\mathbf{2 5}$ & $\mathbf{3 0}$ & $\mathbf{3 5}$ \\
\hline $\begin{array}{l}\text { Balcony } \\
\text { cantilever } \\
\text { beam }\end{array}$ & 2.034 & 1.953 & 2.913 & 2.31 & 2.61 & 3.05 & 3.38 \\
$\begin{array}{l}\text { Room beam } \\
\text { Floor }\end{array}$ & 1.59 & 1.84 & 1.90 & 1.57 & 2.54 & 2.32 & 1.87 \\
bottom & 0.164 & 0.0456 & 0.04 & 0.066 & 0.075 & 0.06 & 0.101 \\
\hline
\end{tabular}

According to the detection results about cantilever beam, floor, and room beam, three different parts in building show that chloride ion concentration of balcony cantilever beam portion is highest and the maximum value is $3.38 \%$. However, the "Concrete quality control standard" (GB50164-92) stipulates in 
the humid, and the environment containing chloride ions in reinforced concrete shall not exceed $0.1 \%$ of the cement weight. The statement of reasons may be obtained that because the locally available raw material saves the cost when used for the building construction at that time, sea sand with high concentration of chloride ion in the raw material, low-tech construction, and inappropriate sand washing process result in the uniform distribution of chloride ion content in building components.

\section{APPLICATION OF THE DURABILITY IMPROVEMENT METHOD IN AN ISLAND VILLAGE BUILDING}

\subsection{Island constructions' BIEM unattended system}

Because island traffic is inconvenient, it is difficult to collect and analyze the data regularly as in the urban infrastructure projects. The research and development of remote control system based on $3 G$ network realizes remote controlling process and real-time grasping BIEM advancement, which completes the entire durability improvement process with a minimal human intervention.

BIEM life extension control system is mainly used to automatically record the natural potential of steel reinforcement before and after repaired, constant control of reinforced current density, dynamic control of system output voltage, and other leakage protection, power-off memory function designs.

\subsection{The application of BIEM in island building}

The $500 \mathrm{~L}$ rust inhibitor in island village buildings of BIEM project was used to ensure that the slab and beam can better immerse with rust inhibitor for BIEM. Laying stainless steel mesh at the bottom surface of test piece as anode, built-in steel bar as cathode, and the bottom of stainless steel is laid on a water preserving layer, the bottom is a plastic film to prevent rust inhibitor loss, which is conducive to the $\mathrm{pH}$ of electrolyte maintain at 10 . Galvanizing 15 days with constant current regulated DC power supply, the current density is $3 \mathrm{~A} / \mathrm{m}^{2}$. Electric time was controlled by a remote control system based on $3 G$ network to monitor and check BIEM data in real time.

\section{CONCLUSION AND PROSPECT}

The durability damage of concrete members caused by chloride ion erosion in the marine environment is often more serious than in the atmospheric environment. This paper based on the investigation of an island village construction group found a large area of serious erosion buildings that is still in use, made detection and analysis of the concrete durability caused by chloride ions erode in the marine environment, and developed a complete set of BIEM system to enhance the construction durability. The testing and evaluation of the topic and durability lift test are summarized as follows:

1. Due to the different roles of marine environment on different locations of the concrete structure, in addition to the parts of building material as raw material, it leads to chloride ion content in the highest part that has been far more than $0.1 \%$ as "Concrete quality control standard" (GB50164-92) specified and the high content of chloride ion is easy to accelerate the corrosion of steel bar.

2. The development of remote control BIEM system with an unattended technique and a self-power supply technique can be suitable for special island environment, studying the durability of island buildings, and successfully putting into use in good operating condition.

Our country has a huge number of islands. Service time of existing island buildings impact by marine environment is shorter than designed. This paper put forward the method of durability improvement, which can overcome the special island environment, so as to improve the durability of the island building and the residential safety index. Accumulate data to optimize BIEM subsystems through the project, in order to be more efficient and energy saving apply to more island buildings durability improvement.

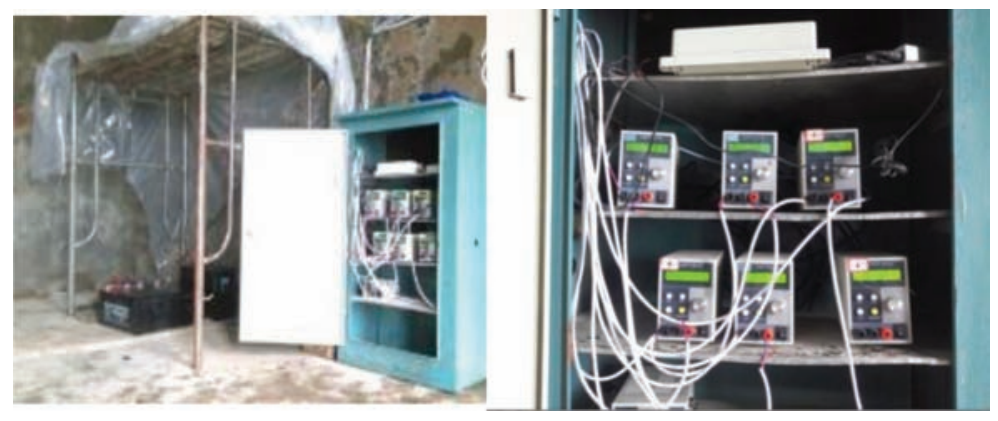

Figure 2. BIEM control system. 


\section{ACKNOWLEDGMENTS}

This paper was supported by the National Natural Science Foundation of China (Grant No. 51408544, 51408534), the Natural Science Foundation of Zhejiang Province (Grant No. LQ14E080007, LY15E080025), and the Ningbo Scientific and Technological Innovation Team (Grant No. 2011B81005).

\section{REFERENCES}

Ding, W., \& Cui, G.-H. (2000). Estimation of initial crack time of concrete protective layer caused by steel corrosion. Construction Technique, 29(5).

Jin, W.-L., \& Zhao, Y.-X. (2001). Study on the mechanism of reinforced concrete members with uniform steel corrosion. Journal of Hydraulic Engineering, 7.

Jin, W.-L., \& Zhao, Y.-X. (2002). Durability of concrete structure. Science Press.

Jin, W.-L., Wu, H.-T., Xu, C., et al. (2015). Research progress on durability of reinforced concrete structure. Development of Water Conservancy and Hydropower Science and Technology, 35(5), 68-76.

Li, T., \& Liu, X.-L. (1999). Analysis and design of concrete structure durability. Beijing: Science Press.

Mehta, P. K. (1991). Concrete durability: Fifty years progress. Proceedings of 2nd International Conference on Concrete Durability. ACI SPI
26-1, Montreal, QC, Canada, 4-9 August 1991; pp. 1-32.

Nmai, C. K. (2004). Multi-functional organic corrosion inhibitor. Cement and Concrete Composites, 26(3), 199-207.

Wei, R. (2001). Mechanics property experiment on building material made of steel under the corrosion. Journal of Fujian College of Architecture \& C E, 3(3/4), 37-42.

Xu, C., Jin, W.-L., \& Zhang, S.-Y. (2014). Preliminary study on service life extension of concrete structures under chloride environmentelectromigration and corrosion inhibition performance of six amine-based inhibitors in concrete. Journal of Building Materials, 5(17), 761-767.

Yan, P.-Y., You, T., \& Cui, L. (2000). The control factors of the corrosion rate of the steel in the high concentration chloride ion concrete. Industrial Buildings, 30(5).

Zhang, S.-Y. (2012). A study of corrosion inhibitors for bidirectional electromigration rehabilitation. Hangzhou: Zhejiang University.

Zhao, T.-J., \& Wan, X.-M. (2001). Method for predicting chloride ion diffusion coefficient of concrete. Industrial Buildings, 31(12).

Zhao, Y.-X., \& Jin, W.-L. (2002). Experimental study on bond constitutive relation between steel bar and concrete. Journal of Architectural Structure, 23. 